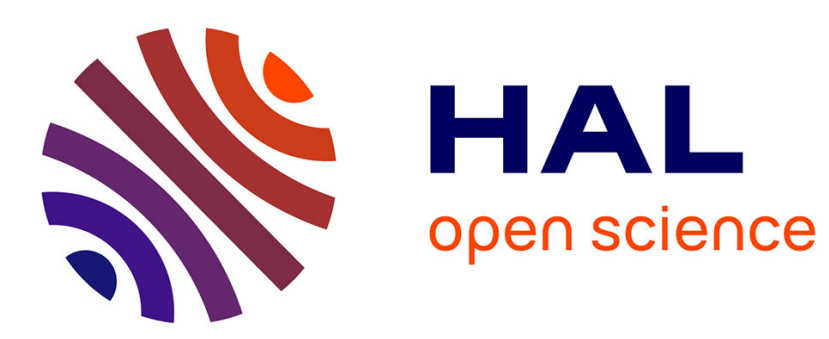

\title{
Supporting Museum Co-visits Using Mobile Devices
}

\author{
Yann Laurillau, Fabio Paternò
}

\section{To cite this version:}

Yann Laurillau, Fabio Paternò. Supporting Museum Co-visits Using Mobile Devices. Mobile Human-Computer Interaction - MobileHCI 2004, Sep 2004, glasgow, United Kingdom. pp.451-455, 10.1007/978-3-540-28637-0_55. hal-03286447

\section{HAL Id: hal-03286447 \\ https://hal.science/hal-03286447}

Submitted on 14 Jul 2021

HAL is a multi-disciplinary open access archive for the deposit and dissemination of scientific research documents, whether they are published or not. The documents may come from teaching and research institutions in France or abroad, or from public or private research centers.
L'archive ouverte pluridisciplinaire HAL, est destinée au dépôt et à la diffusion de documents scientifiques de niveau recherche, publiés ou non, émanant des établissements d'enseignement et de recherche français ou étrangers, des laboratoires publics ou privés. 


\title{
Supporting museum co-visits using mobile devices
}

\author{
Yann Laurillau, Fabio Paternò \\ Consiglio Nazionale delle Ricerche (CNR-ISTI), \\ Via G. Moruzzi 1, 56100 Pisa, Italy \\ \{Yann.Laurillau, Fabio.Paterno\}@isti.cnr.it
}

\begin{abstract}
The goal of this work is to provide tools that promote social interactions between visitors through cooperative and educational games. In this paper, we describe how to support collaborative learning in museum visits and show an example application based on mobile palmtop systems. To this end, we have developed a system that is able to support collaborative and independent activities, and offer context-aware content.
\end{abstract}

\section{Introduction}

The wide dissemination of mobile technologies, such as cell phones or handheld personal digital assistants (PDAs), offers a good opportunity to get groupware applications out of the laboratories and develop new kinds of groupware applications which are no longer reserved for professionals and desktop computers. Mobile devices are becoming real social media, particularly in terms of communication. Such technologies are means to explore collaborative activities and move groupware applications to public settings, such as museums.

The museum visit is usually perceived as an individual experience. Furthermore, electronic guides or interactive systems in museums are not designed to promote social interaction among visitors. However, the museum experience, according to Falk and Dierking [3], is influenced by the social context, which includes interactions between visitors. In addition, many studies have highlighted the fact that interactions with the exhibit, as well as communication and social interaction between visitors are also key points of a successful learning environment [6] [7].

The research on social interaction and collaboration using new technologies is quite recent. Interest has grown with the evolution of mobile devices. In addition, there has been a change in the design of museum exhibitions in an increasing number of projects: little by little, the museum experience is considered as a collaborative activity and, more and more, museums are designed to support and encourage group interactions.

In this work, our goal is to promote interaction and communication between visitors through cooperative and interactive educational games, based on sharing, and using handheld PDAs. In this context, museum interactive systems are embedded in an electronic companion rather than being static fixtures in the museum. In addition, interactivity is considered at the visit level and not only at the artwork level: visitors are able to pace the visit and interact in the museum according to their desires. Furthermore, educational games are an interesting and entertaining way to initiate and 
promote collaboration between visitors. For example, the Ghost ship project [5] shows that playing and exploring artwork may help visitors to initiate collaboration. However, in this project, the Ghost Ship is a single interactive artwork and the approach should be extended to all the artworks in the museum.

In order to obtain a new solution, we have developed and deployed an interactive system, the collaborative extension of the portable Cicero [2], dedicated to supporting the visit of the Marble Museum of Carrara. This system enables communication, sharing and collaboration among visitors, and also offers context-aware and personalized content. In the rest of the paper, we detail the main ideas of this project and provide a short review of related work. We then introduce our approach to support covisiting in museum environments through PDAs. In the third part, we describe our system, the portable Cicero system.

\section{Museum Co-Visiting}

Museum co-visiting has been considered in a number of projects. The Sotto Voce project [4], developed at Xerox PARC, is a mobile companion, based on the iPaq technology, that provides audio content of artwork descriptions and acts as an audio media space between visitors, which offers a mean for awareness and sociability. The authors have identified four kinds of activity: (i) shared listening, in order to promote interaction and communication between companions; (ii) independent use, in order to enable temporarily or entirely the switching off of the shared listening, in particular when visitors do not want to engage social interactions; (iii) following, when a companion is in charge of driving, implicitly or explicitly, the tour; (iv) checking in, which is a short activity, to maintain and update the shared context.

The City project [1], part of the Equator project, takes place at the lighthouse in Glasgow, a museum dedicated to the work of the designer Mackintosh. The system considers three kinds of technology: (i) a real visit using a PDA; (ii) for the virtual reality visit in a 3D world; (iii) for the Web visit. With this system, visitors are able to share their museum experience visit and navigate jointly through mixed realities: the Web, the virtual and physical reality. Information is provided about each visitor location and orientation. In addition, they may communicate through audio channels. The authors have observed that voice interaction, location and orientation awareness, and mutual visibility are essential to the success of museum co-visiting between remote users.

The Ghost Ship project [5], compared to the previous projects, is more oriented to an artistic experience of the museum co-visiting. The goal of this work is to analyse and consider informal and social interactions between visitors through video interaction recordings. The Ghost Ship installation is a dedicated room of the SOFA exhibition containing a wood painted ship, wooden figures, a simulated desk and an "inside the ship" area. Some of the ship portholes are video portholes which record and show visitor's behaviours and interactions with the ship. In addition, microphones capture visitor comments about their actions and about what they can see on the video portholes. The authors observed that the Ghost Ship helps visitors to break the ice more easily and to play with and explore collaboratively the ship. 
Compared to the Equator City project, we consider "physical" visitors moving in the real museum while they consider a mixed visit combining the real museum and a virtual representation of the museum (in a 3D representation or through a Web site). Some of the existing projects consider pure collaborative virtual visits as Web covisiting such as the Van Gogh museum. The authors of the Equator City project, as in the Sotto Voce project, have noted that information about location and orientation of the companions (checking in task) is essential in a cooperative visit in order to maintain group awareness. This point has been considered in our project, as detailed in the next section: visitors are able to check for their companion and are aware about the state of the cooperative game.

\section{The Cicero Project}

Cooperative visiting through educational games, as explained in the introduction and highlighted by the authors of the Ghost Ship project, is an interesting way to promote co-visiting and to engage visitors to share their museum experience. In addition, it may also preserve the individual aspects of the museum experience as highlighted by the authors of the Sotto Voce project. However, audio sharing, as described and implemented in Xerox's project, may lead too much to a passive collaboration between companions such as the following or checking in tasks.

In this project, our goal is to design a new interactive and multi-user system for mobile devices that is able to support and promote social interactions in museums through collaborative activities (CSCW) based on educational games. We consider the gaming approach as means to learn things about the museum in an entertaining context. However, our work is driven by $\mathrm{HCI}$ and $\mathrm{CSCW}$ issues rather than educational issues. In our system, we consider two kinds of cooperative games: one to support explicitly cooperation and sharing; and one to support implicitly cooperation through individual activities. The first kind of cooperative game is similar to enigma or treasure hunt games: visitors have to gather clues and to solve cooperatively enigmas in order to find the solution and to find a particular artwork in the museum. This game needs visitors to share and to debate about what they have seen and learned during the visit. The second kind is a collection of educational games to discover the museum, at the individual level, all along the visit and to gather clues. Indeed, solving an individual game would provide clues to solve the shared enigma (solving a puzzle and answering to a quiz) and would provide awareness information about each visitor's activity. In addition, each visitor can pace its own visit: the group interaction is not highly coupled and the system supports mixed synchronous and asynchronous modes. A scenario is provided at the end of the section, in order to illustrate both kinds of games and how explicit and implicit collaboration is supported.

During the visit, at any time, visitors can use the museum map and the peripheral information about other visitors in order to share their clues and try to solve the shared enigma. In addition, visitors are able to submit solutions, which are validated when visitors need to meet each other and to discuss about the solution. However, in order to stimulate visitors to play with our interactive electronic guide, and their name appear in the fame list in function of the number of points accumulated during the visit: if they cooperate a lot, they receive a proportional number of points. 
Designing a user interface in the context of the museum visit is not an easy task because that kind of software will be used only one time by a visitor for one or two hours: the interface must be highly intuitive and affordable at first sight. It is, in one sense, a throw-away interface. For this reason, we have tried to avoid a cognitive and visual overload of the new user interface, and we added only few icons, as shown in Figure 1(a), in order to provide information about other users and the group activity, as well as about the available games. In the new interface, visitors are identified by their name and by a coloured bullet. In addition, coloured bullets $\bullet$ indicate what items had been seen by other visitors. An icon representing a ? symbol indicates that an interactive game is associated with the related artwork, which had not been already solved. The following icon $815 \mathrm{pts}$, representing two little men, indicates the current score of the group. Finally, a click on the button 95 in the command bar, at the bottom of the screen and representing two little men and a piece of jigsaw, leads to the shared enigma screen described below.
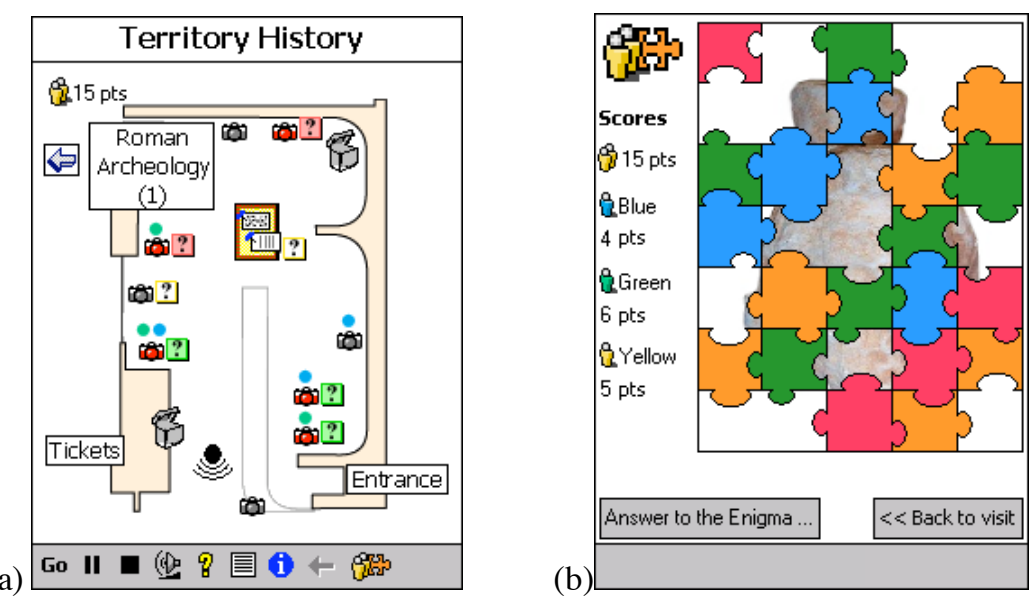

Fig. 1. (a) View of the current room (b) Puzzle part of the shared enigma.

In Figure 1(b), we present an example of shared enigma: the goal is to find which artwork is hidden by puzzle pieces and to answer to a quiz about this artwork. Each time a visitor finds a clue for the shared enigma, a puzzle piece is removed and a piece of information about the artwork is made available. On the left part of the screen, the system indicates the current score and how many points each visitors have gained. In addition, visitors are able to answer questions about this artwork even if there are still puzzle pieces hiding parts of the image. At any time, the visitors can decide together to provide and validate a common answer to solve the shared enigma, based on the set of clues gathered during the visit. To illustrate this, let us consider the following scenario: Fabio (blue player), Yann (green player) and Carmine (yellow player) are visiting the Marble Museum and have decided to play together during the visit; the goal of the shared enigma is to find the artwork representing the statue of goddess Luni and to answer some questions about it, such as "who was Luni ?" (a goddess, protecting the colony of Luni, living near the town of Carrara). During the visit, 
Fabio is playing some educational games. For example, one is to associate a type of marble with the right picture; another one is to play with letters in order to find the author of Vicarius' epigraph. Fabio has solved these games and has gained two clues that are automatically shared with Yann and Carmine: two pieces of information about the statue ("it represents a goddess" and "she was the protector of a colony"); in addition, two puzzle pieces, as shown in Figure 1(b), are removed and the middle part of the statue is now visible. At that point, Yann and Carmine are aware that new clues have been found, as indicated by the "two little men" icon $815 \mathrm{pts}$, which is updated to indicate the new score, as shown in Figure 1(a). Yann has found which artwork is hidden by the puzzle using the clues discovered by Fabio, but the questions still remain unsolved. Yann asks Fabio and Carmine if they have any idea. Based on the clues, they discovered that the sculpture represents a goddess, protector the colony of Luni: the shared enigma is solved.

\section{Conclusion and future work}

In this paper, we have presented a system that enables and supports co-visiting at the Marble museum of Carrara. Compared to the existing works, the novelty of our project is to promote communication and social interactions between visitors based on interactive and cooperative educational games embedded in mobile devices such as iPaq PDAs. Furthermore, with this system, we consider the individual museum experience and visitors can regulate the pace of their own visits more flexibly than in solutions as those proposed by the Sotto Voce project where companion visitors share the audio comments. Finally, early feedback from the users has been encouraging. However, more formal tests are being currently conducted in order to improve our system.

\section{References}

1. Brown, B., MacColl, I., Chalmers, M., Galani, A., Randell, C., and Steed, A., Lessons from the Lighthouse: Collaboration in a Shared Mixed Reality System, in Proc. ACM CHI'03, 2003, p. 577-584, ACM Press.

2. Ciavarella, C., and Paternò, F., Design Criteria for Location-aware, Indoor, PDA Applications, in Proc. of Mobile HCI'03 Conference, 2003, p. 131-144, Springer Verlag.

3. Falk, J.H., and Dierking, L.D., Learning From Museums, Visitor Experiences and the Making of Meaning, 2000, 288 p., Rowman \& Littlefield.

4. Grinter, R., Aoki, P., Hurst, A., Szymanski, M., Thornton, J., and Woodruff, A., Revisiting the Visit: Understanding How Technology Can Shape the Museum Visit, in Proc. ACM CSCW'02, 2002, p. 146-155, ACM Press.

5. Hindmarsh, J., Heath, C., Vom Lehn, D., and Cleverly, J., Creating Assemblies: Aboard the Ghost Ship, in Proc. CSCW'02, 2002, p. 156-165, ACM Press.

6. Hindmarsh, J., Heath, C., Vom Lehn, D., Ciolfi, L., Hall, T., and Bannon, L., Social Interactions in Museums and Galleries, in Deliverable of the Shape Project, D2.1, 2001, Chapter 2, p. 9-23, Disappearing Computer Project.

7. Leinhardt, G., and Crowley, K., Objects of Learning, Objects of Talk: Changing Minds in Museums, in S. Paris (Editors), Multiple Perspectives on Object Centered Learning, 2002, p. 301-324, Lawrence Erlbaum Associates. 